\title{
Investigación y tratamiento de la Virgen de los Remedios de Villarrasa (Huelva)
}

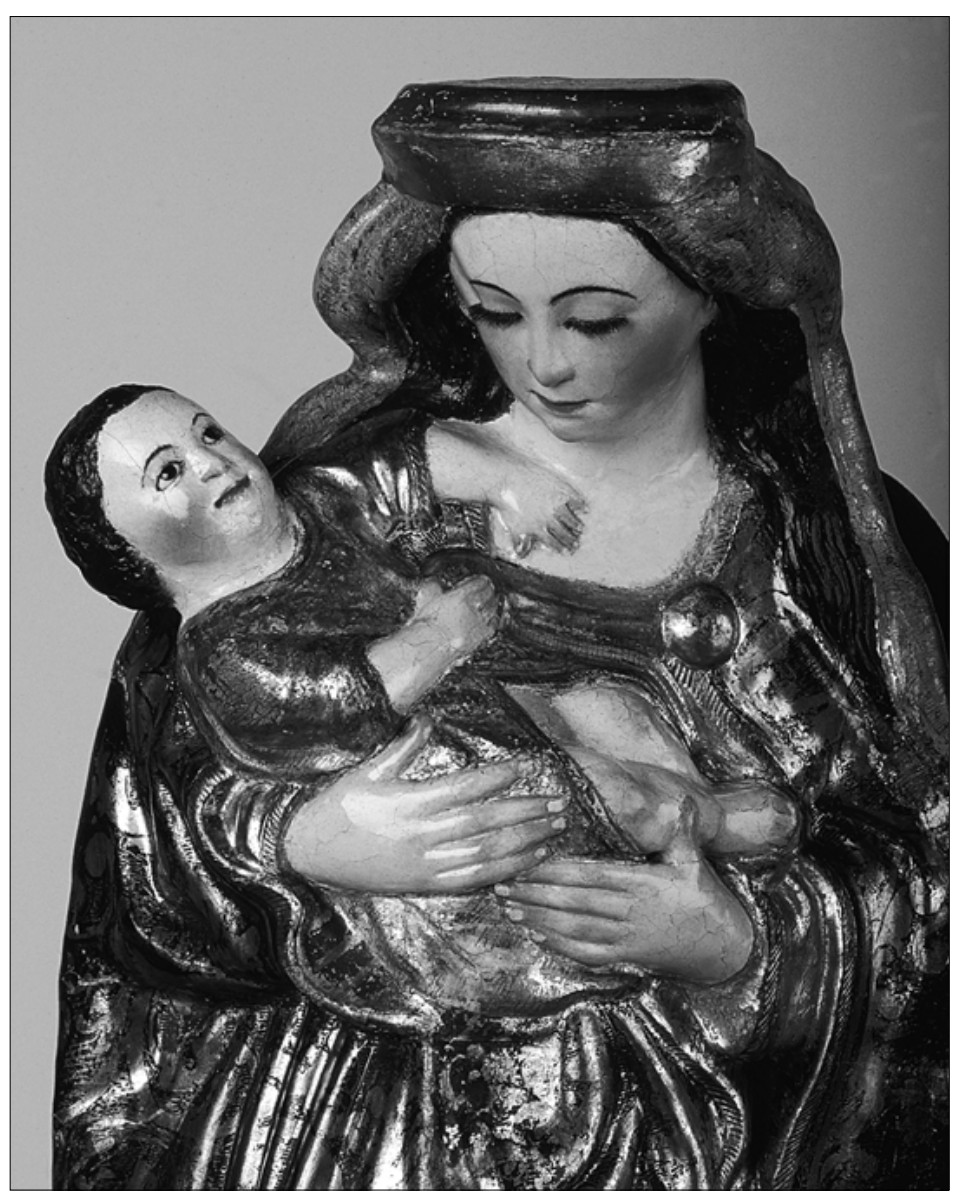

Eva Villanueva Romero

Historiadora del Arte. Dpto. de Investigación Centro de Intervención del IAPH

\section{Gracia Montero Saucedo}

Restauradora. Dpto. de Tratamiento Centro de Intervención del IAPH

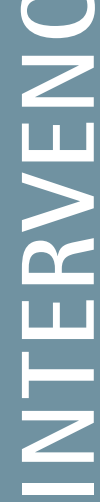

dad de Villarrasa (Huelva) de la que es patrona y titular de su hermandad.

Esta obra responde al tipo iconográfico denominado "Mater Amabilis" representando un momento de gran intimidad y naturalismo. La Virgen de pie sostiene al Niño en su brazo derecho en vez de en el izquierdo, como es lo usual en estas imágenes, mientras el Niño le lleva la mano al pecho. (Fotol)

Los tratamientos de conservación-restauración de la imagen se llevaron a cabo en los talleres del Centro de Intervención del Instituto Andaluz del Patrimonio Histórico durante los meses de enero a julio de 1998.

En este artículo se resume la memoria generada durante el proceso de intervención así como la investigación histórico-artística comparativa con otras esculturas similares localizadas. 
$\longleftarrow$
$\square$
$\square$

\section{Estudio histórico-artístico}

La leyenda sobre el origen de la Virgen de los Remedios parte del manuscrito redactado por fray Felipe de Santiago en 17/4 y es reflejado posteriormente en el libro capitular del cabildo secular del año 1740 I.

Según esta leyenda, el 18 de diciembre de 1503 dos jóvenes se presentaron pidiendo acogida en la curti-

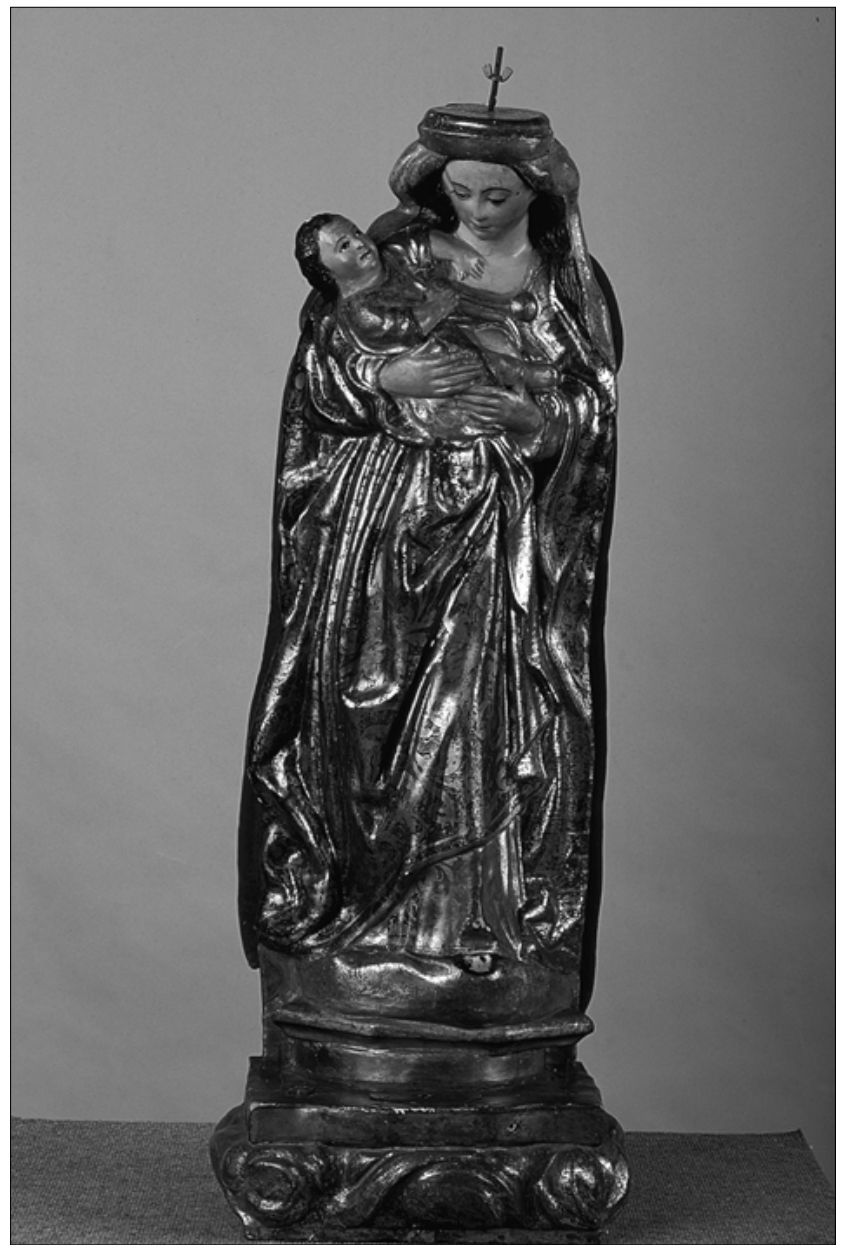

2. Virgen de Hornillos Valladolid. Desaparecida.

3. Virgen de Prádanos de Bureba. Burgos. Desaparecida.
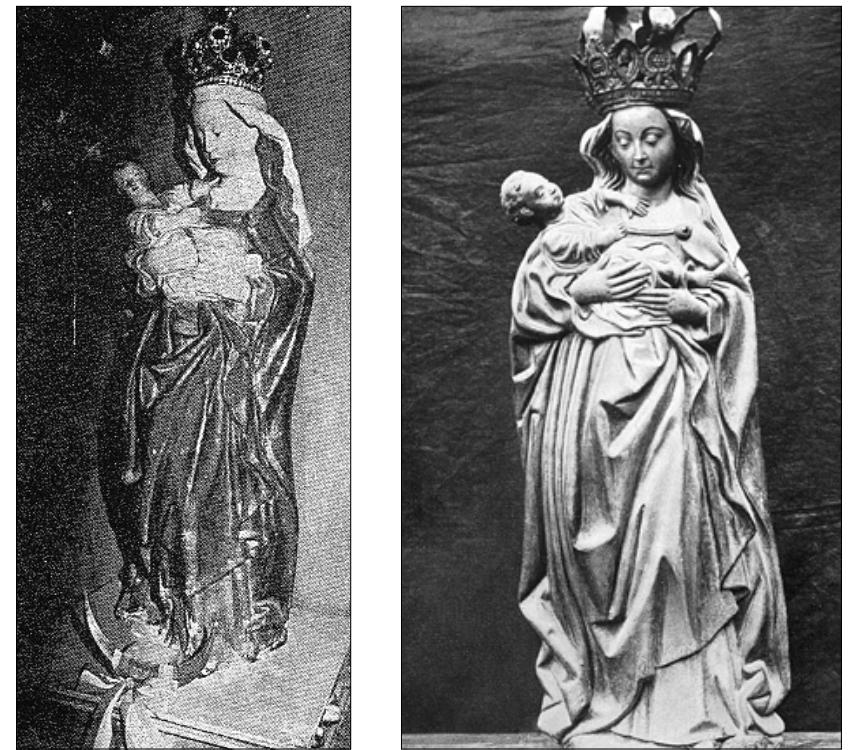

duría de un comerciante de Villarrasa llamado Pedro de la Cruz, el cual había sido calumniado y denunciado por sus enemigos a la justicia. El comerciante les dio hospedaje y a cambio los jóvenes le entregaron una imagen de la Virgen diciéndole en el momento de la entrega que le hiciese iglesia con hospital, que Ella era su remedio y así debía llamarse. Añadieron además que le habían entregado otra a los monjes jerónimos con el título de la Luz, refiriéndose a la Virgen de la Luz de Lucena del Puerto (Huelva).

Está documentada que la erección canónica del monasterio de la orden jerónima de Lucena del Puerto se llevó a cabo en el año 15002 .

Aunque no conocemos cuál es el origen de la Virgen de los Remedios dada su semejanza con la Virgen de la Luz de Lucena del Puerto, podemos suponer una misma procedencia relacionada posiblemente con la orden jerónima.

También hay que añadir que la comunidad jerónima mantuvo una estrecha relación con los nobles y reyes de Castilla gozando de un gran prestigio durante los siglos XV y XVI. Fueron los Reyes Católicos quienes intercedieron a favor de la orden para que se llevara a cabo la fundación de este monasterio.

Con respecto a su morfología la Virgen de los Remedios está concebida como un alto relieve al tener su lado posterior plano. Adelanta la pierna izquierda asomando la punta del zapato por debajo de la túnica y muestra una leve incurvación del torso hacia la derecha equilibrando la figura al inclinar la cabeza hacia el lado contrario. Esto es un rasgo propio de las imágenes realizadas en el periodo de transición de la fórmulas góticas a las renacentistas.

En las vestimentas de la Virgen se aprecian características de la indumentaria mariana del siglo XV como por ejemplo la forma de llevar el manto resbalando suelto por el lado izquierdo, en cambio por el derecho, cruza por delante y envuelve casi toda la imagen formando angulosos pliegues.

Esta moda era frecuente en las imágenes marianas del gótico europeo del siglo XIV y se comenzó a usar en la península a partir del primer cuarto del siglo XV. Al final de este siglo corresponde también el tipo de escote de la túnica en forma cuadrada 3 .

La manera de sujetar el manto a la altura del pecho mediante un cordón unido a ambos lados por un broche es típica en el traje occidental del siglo XIII, pero se continuó empleando en siglos posteriores con algunas variantes. $Y$ es al parecer una moda de origen germánico ${ }^{4}$

Por otra parte el Niño va vestido con túnica talar abierta hasta la cintura.

Al realizar el análisis estilístico de la Virgen de los Remedios y su estudio comparativo con otras obras pertenecientes a la misma época, hemos encontra- 
do una serie de grafismos comunes en varias imágenes marianas dispersas por diversos lugares de la península.

Entre ellas, dos Vírgenes con el Niño que actualmente no se conservan. Una pertenecía al pueblo de Hornillos en Valladolid y la otra a la localidad burgalesa de Prádanos de Bureba, esta última realizada en barro cocido. Eran obras de pequeño tamaño pues no llegaban a medir ninguna de las dos los $80 \mathrm{~cm}^{5}$. (Fotos 2 y 3 .)

Se advierte en ambas esculturas la misma incurvación del torso y la inclinación de la cabeza que tiene la de los Remedios, además de ser idéntica la postura del Niño y la disposición de las vestimentas.

En Andalucía se conservan dos imágenes cuya semejanza es aún mayor, la Virgen de la Luz de Lucena del Puerto (78 cm de altura) y la Virgen del Socorro de Antequera $(89,5 \mathrm{~cm}$ de altura). Además de los rasgos comentados anteriormente, se aprecia al estudiarlas detenidamente cómo reproducen de igual manera todos los pliegues de las vestimentas o la forma de las manos con los dedos largos y finos. Incluso tienen prácticamente la misma altura que la Virgen de los Remedios $(88 \mathrm{~cm}$ de altura). (Fotos 4 y 5 .)

A estos datos histórico-artísticos hay que añadir los proporcionados por los análisis radiográficos y del tipo de material en que está realizada la escultura que más adelante se detallan.

A través de ellos hemos podido conocer que la Virgen está realizada a partir de un molde utilizado para conformar los volúmenes escultóricos mediante pasta de papel y telas encoladas. En su interior se sostiene por un armazón de madera.

También hemos tenido ocasión de realizar radiografías a la Virgen de Antequera y se ha constatado que la técnica de ejecución del soporte es idéntica en ambas obras ${ }^{6}$. Además presenta su lado posterior plano constituido por una tabla al igual que la Virgen de los Remedios. (Foto 6.)

Probablemente estas tres imágenes marianas fueron ejecutadas por el mismo artista tomando como modelo una escultura castellana inspirada a su vez en una obra de origen nórdico. Hay que tener en cuenta que desde el comienzo del siglo XV el comercio de objetos artísticos entre Flandes y España estaba bien organizado, no solamente en los puertos del norte y de levante sino también en Castilla.

De hecho se han encontrado, aunque en menor medida, ciertas características estilísticas semejantes entre la Virgen de los Remedios y una Virgen con el Niño realizada en barro cocido y fechada en el siglo $X V$, cuya procedencia es alemana (Westfalia) ${ }^{7}$. Se observa cómo el Niño está colocado en el mismo lado, la forma de las manos es semejante y además es idéntica la manera de abrochar el manto. (Foto 7.)
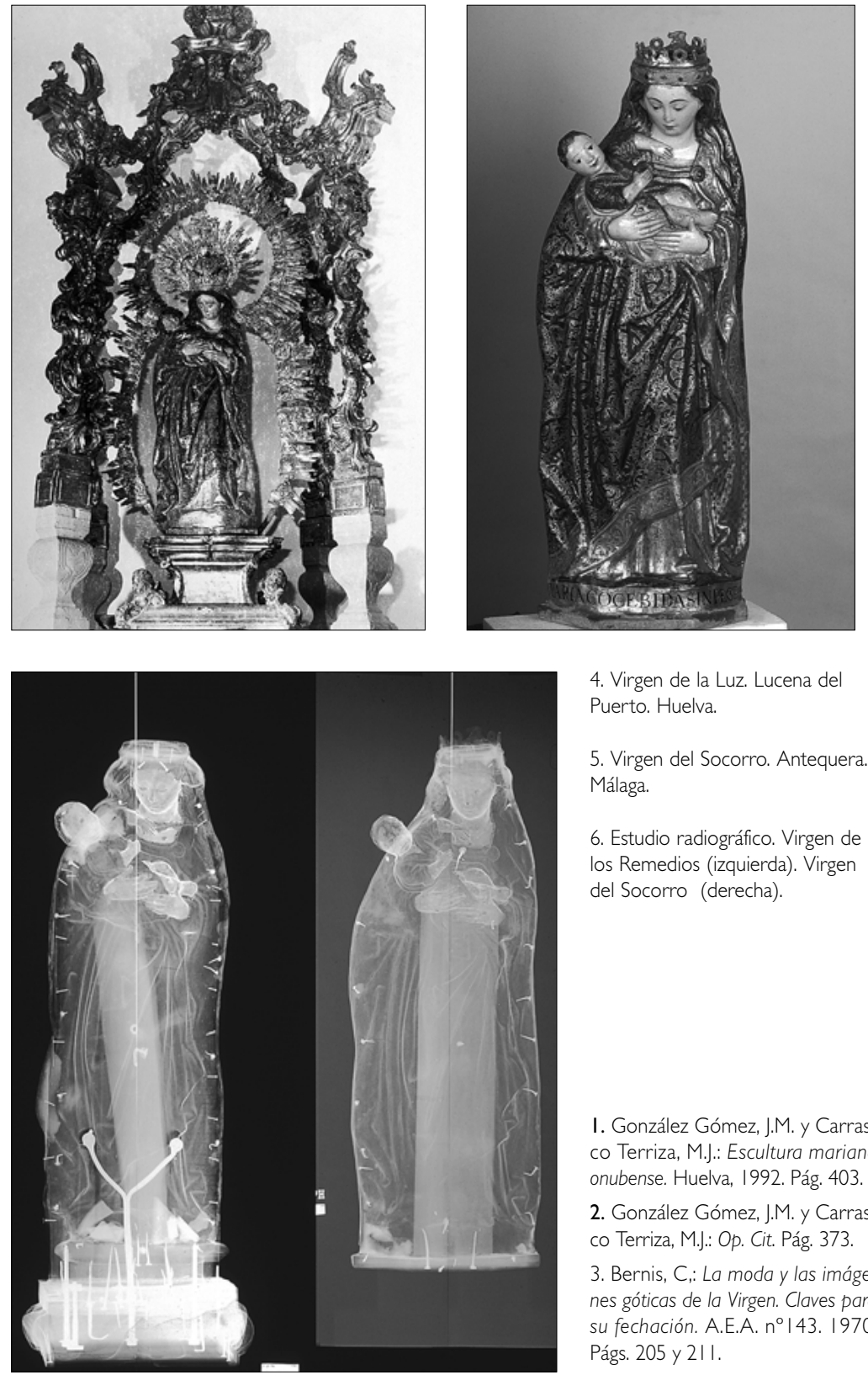

4. Virgen de la Luz. Lucena del Puerto. Huelva.

5. Virgen del Socorro. Antequera. Málaga.

6. Estudio radiográfico. Virgen de los Remedios (izquierda). Virgen del Socorro (derecha)

I. González Gómez, J.M. y Carrasco Terriza, M...: Escultura mariana onubense. Huelva, 1992. Pág. 403.

2. González Gómez, J.M. y Carras co Terriza, M.j.: Op. Cit. Pág. 373.

3. Bernis, C,: La moda y las imágenes góticas de la Virgen. Claves para su fechación. A.E.A. n| 43. 1970 Págs. 205 y 211

4. Bernis, C.: Op. Cit. Págs. 205 y 206.

\section{Estudio científico-analítico}

Finalizada una primera observación visual de los diferentes estratos constituyentes de la escultura, mediante luz normal y lupa de aumento, y de forma previa a los tratamientos de conservación - restauración, fueron llevados a cabo una serie de estudios por el Departamento de Análisis del IAPH. Estos exámenes sirvieron para profundizar en el conocimiento tanto de la técnica de ejecución de la escultura como de su estado de conservación, con el objeto de realizar seguidamente la propuesta de intervención.

\section{Documentación fotográfica}

En primer lugar se llevó a cabo un amplio reportaje fotográfico y macrofotográfico mediante iluminación normal y rasante con el fin de documentar el estado
5. La Virgen de Hornillos está publicada en: Ara Gil, C.:Escultura Gótica en Valladolid y su provincia. Simancas, 1977. Pág. 390. Lámina CCXXXIV, 3 y en Martín González, J.J.: Inventario artístico de Valladolid y su provincia. Valladolid, 1970 Pág. 143. Lámina 131. La Virgen de Prádanos de Bureba aparece en Weise, G.: Spanische plastik aus sieben Jahrhunderten. Reutlingen, 1927. T. II, I. Pág. 87. T.II, 2. Lámina 94.

6. Agradecemos al Excmo. Señor don Jesús Romero, Alcalde de Antequera y a doña Marisa Olmedo, conservadora-restauradora, los datos que nos aportaron sobre Virgen del Socorro y habernos facilitado realizar un estudio radiográfico de esta obra.

7. Weise, G.: Op. Cit. T. II, I. Pág. 87. T.Il, 2. Lámina 95. 
$\longleftarrow$
$\square$
$\square$

7. Virgen con el Niño. Westfalia.

8. En la fotografía de ultravioletas se evidencian los repintes sobre las carnaciones.

9. Detalle de la radiografía. Se aprecian las dimensiones de la laguna localizada en el escote.
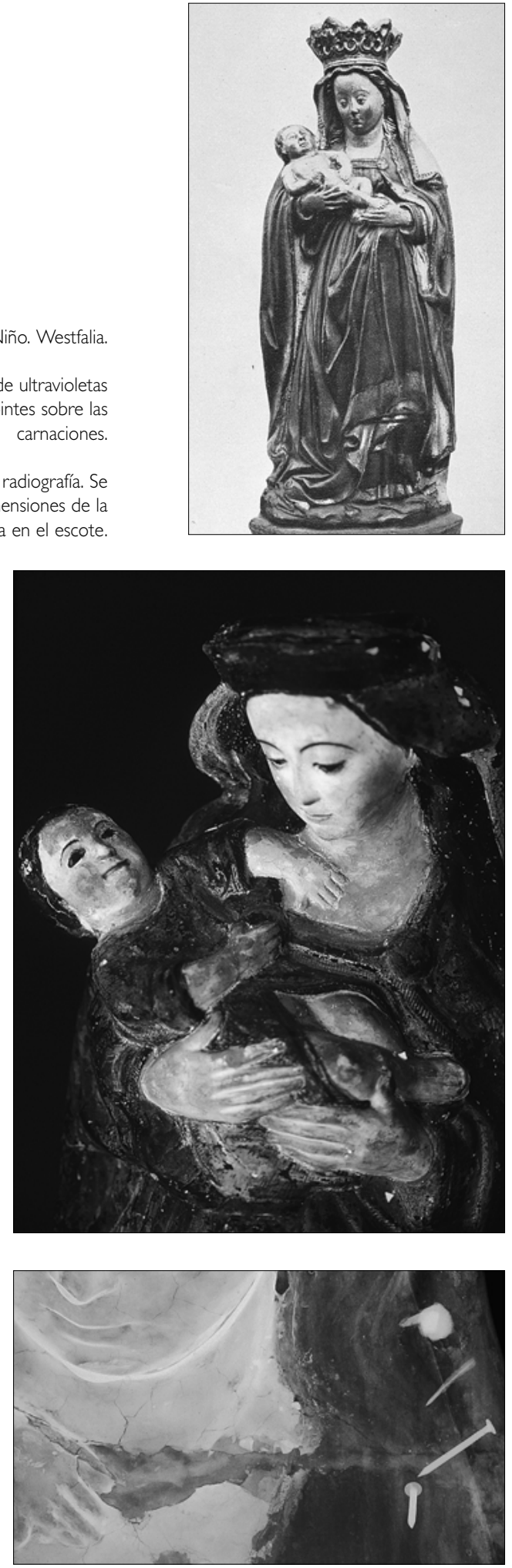

inicial de conservación que presentaba la obra así como su técnica de ejecución.

El examen de la superficie policroma con radiación ultravioleta fue registrado fotográficamente detectándose numerosos repintes parciales repartidos puntualmente sobre toda la obra y de forma generalizada recubriendo parte de las carnaciones de la Virgen y del Niño. (Foto 8.)
La fluorescencia reflejada por la radiación ultravioleta también evidenciaba acumulaciones del barniz en superficie.

\section{Estudio radiográfico}

Se realizaron radiografías de la escultura frontal y de perfil que aportaron interesantes datos por un lado sobre su técnica de ejecución y por otro sobre el estado de conservación del soporte y policromía.

El volumen escultórico no es macizo, apreciándose un núcleo central de madera que con una ligera inclinación recorre longitudinalmente el interior. Dentro del cuerpo del Niño aparece otro núcleo cuadrangular e inclinado con respecto al eje vertical. En la radiografía realizada a la Virgen del Socorro de Antequera encontramos numerosas similitudes en la técnica constructiva de los volúmenes escultóricos. (Foto 6)

Mediante la radiografía se revelaron las dimensiones y localización exacta de la laguna, ubicada en el escote de la Virgen, que quedaba oculta por el repinte generalizado superpuesto a la policromía en esta zona. (Foto 9.)

\section{Estudio analítico de los materiales constitutivos}

Los análisis químicos y biológicos realizados han permitido conocer la naturaleza de los materiales tanto originales como añadidos que constituyen los diferentes estratos de la escultura:

\section{Identificación de las fibras textiles del soporte}

Fueron extraídas un total de cuatro muestras de fibras procedentes del soporte de la escultura aprovechando las lagunas de la policromía. Una vez preparadas las muestras se identificaron al microscopio óptico observando la sección transversal y longitudinal de las fibras.

Se detectaron fibras de lino tanto en la trama como en la urdimbre del soporte de tela encolada utilizado en gran parte de la escultura. De igual manera se observó la presencia de fibras de lino en el soporte de pasta de papel empleado para modelar el rostro y manos de la Virgen y la figura del Niño.

\section{Identificación de la madera}

Tras observar al microscopio óptico las secciones transversal, longitudinal radial y longitudinal tangencial de la muestra extraída de la base de la escultura se identifica la madera dentro del género Picea, de la familia de la Pináceas.

Identificación de cargas, pigmentos, aglutinantes, barnices y repintes

Se realizó el estudio estratigráfico de catorce muestras sólidas extraídas de diversos puntos de la policromía aprovechando siempre las zonas de lagunas. Una vez preparadas las muestras embutiéndolas en 
resina acrílica fueron examinadas mediante microscopía óptica fotografiando su sección estratigráfica y midiendo el espesor de los diferentes estratos.

Con el objeto de determinar la naturaleza de las cargas y pigmentos de naturaleza inorgánica fueron examinadas las estratigrafías mediante microscopía electrónica de barrido (SEM) y se realizaron microanálisis por energías dispersivas de Rayos X (EDRX).

La capa de preparación y los diferentes estucos aplicados en intervenciones posteriores presentan una carga de yeso (sulfato cálcico dihidratado) aglutinado con cola animal.

En el estudio han sido identificados los siguientes pigmentos:

\begin{tabular}{ll}
\hline Blanco: & blanco de plomo y blanco de bario \\
\hline Bermellón: & cinabrio o sulfuro de mercurio \\
\hline Azul: & $\begin{array}{l}\text { ultramar } \\
\text { (sulfato de aluminio y sodio con azufre) }\end{array}$ \\
\hline Amarillo: & tierra ocre \\
\hline Pardo: & tierras (ocres y óxidos de hierro) \\
\hline
\end{tabular}

La caracterización de barnices, aglutinantes y repintes de naturaleza orgánica fue efectuada mediante espectroscopía de infrarrojos con transformada de Fourier (FT-IR). Fueron analizadas un total de siete muestras extraídas mediante hisopo, detectándose la presencia de resina shellac o goma laca sobre las carnaciones. $Y$ recubriendo la policromía de la peana se identificaron resinas acrílicas tipo paraloid B72.

\section{Identificación de los agentes biodeteriorantes}

Tras observar la existencia en la base de la escultura de orificios originados por un ataque biológico, no se pudo obtener ningún insecto adulto. Únicamente se apreciaron restos de excrementos e indicios de la presencia de la especie Anobium punctatum De Geer al estudiar el tipo y el tamaño de las galerías.

Fue extraída del soporte y observada al estereomicroscopio una exuvia de larva de Derméstido, coleóptero que ataca materiales orgánicos ricos en sustancias proteicas (textiles, papel etc.).

\section{Datos técnicos}

\section{Soporte}

En la ejecución del soporte escultórico de la imagen de la Virgen de los Remedios ha sido empleada una técnica mixta en la que se combinan materiales de diversa naturaleza: tela encolada, pasta de papel y madera.

El soporte esta constituido principalmente por telas encoladas en prácticamente la totalidad del anverso de la figura, apreciándose el tejido en las lagunas de policromía existentes. Los volúmenes del rostro de la Virgen, las manos y la figura del Niño han sido modelados mediante pasta de papel. Con el estudio analítico se identificaron fibras de lino en la naturaleza del

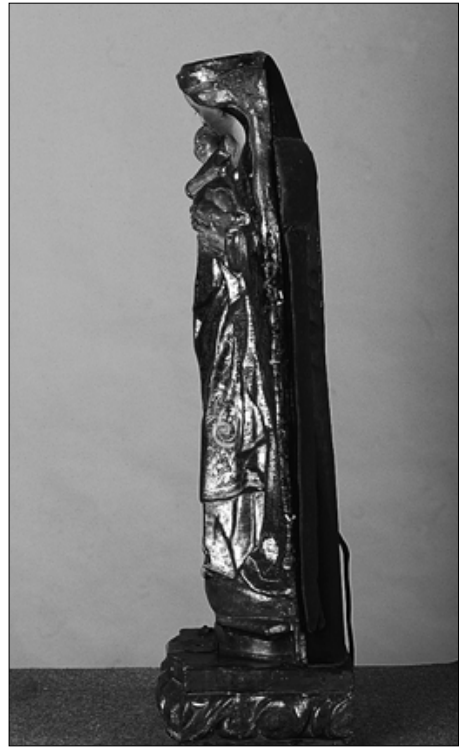

10. Virgen de los Remedios. Vista lateral.

soporte tanto en las telas encoladas como en la pasta de papel.

Como apreciábamos en el estudio radiográfico, en el interior de la escultura existen dos núcleos de madera que sirven de estructura al conjunto de los volúmenes de tela y pasta.

El reverso de la escultura está recubierto por una tabla de madera de $2 \mathrm{~cm}$ de espesor fijada al soporte de tela mediante clavos de forja. Actualmente dicha tabla se encuentra oculta por el volumen también de madera añadido en la intervención de 1988. (Foto I0.)

\section{Preparación, película de color y capa de protección}

El soporte mixto original está recubierto por una capa de preparación de naturaleza magra al igual que los diferentes estratos de preparación correspondientes a intervenciones posteriores. Todos ellos están constituidos por una carga de yeso (sulfato cálcico dihidratado) aglutinado con cola animal. El espesor máximo de este estrato en las muestras analizadas oscila entre 280 y 500 micras.

El aparejo aplicado bajo las carnaciones está constituida por la superposición de una preparación magra (yeso y cola animal) y una imprimación oleosa compuesta por blanco de plomo y aceite de linaza.

Las carnaciones tanto de la Virgen como del Niño han sido realizadas mediante una técnica oleosa. Los pigmentos detectados en su composición coinciden en los diferentes estratos de color, variando en su proporción. Las capas de color están constituidas por albayalde con inclusiones de bermellón y como aglutinante aceite de linaza.

El resto de la superficie policroma ha sido dorada presentando bajo la lámina de oro fino bruñido un estrato de bol rojo, compuesto por silicatos aluminosos o minerales arcillosos con una elevada proporción de óxi- 


\section{ESTUDIO DE CORRESPONDENCIA DE CAPAS POLÍCROMAS}

\begin{tabular}{|c|c|c|c|c|c|c|c|c|}
\hline & $\begin{array}{l}\text { Carnación } \\
\text { Virgen (rostro) }\end{array}$ & Toca & $\begin{array}{l}\text { Base } \\
\text { corona }\end{array}$ & Manto & $\begin{array}{l}\text { Vuelta } \\
\text { manto }\end{array}$ & $\begin{array}{l}\text { Túnica } \\
\text { Niño }\end{array}$ & $\begin{array}{l}\text { Carnación } \\
\text { Niño }\end{array}$ & $\begin{array}{l}\text { Peana } \\
\text { Nube }\end{array}$ \\
\hline Suciedad & Suciedad & Suciedad & Suciedad & Suciedad & Suciedad & Suciedad & Suciedad & Suciedad \\
\hline Barniz & Barniz & & & & Barniz & Barniz & Barniz & Barniz \\
\hline Repinte & $\begin{array}{l}\text { Parcial } \\
\text { Rosa ocre }\end{array}$ & Parcial & & $\begin{array}{l}\text { Parcial } \\
\text { Estofado } \\
\text { Azul }\end{array}$ & & Parcial & Parcial & Parcial \\
\hline \multirow[t]{4}{*}{$\begin{array}{l}\text { Segunda } \\
\text { Policromía }\end{array}$} & \multirow{4}{*}{$\begin{array}{c}\text { Rosa } \\
\text { Imprimación } \\
\text { Blanca }\end{array}$} & $\begin{array}{c}\text { Estofado } \\
\text { Blanco }\end{array}$ & & $\begin{array}{c}\text { Estofado } \\
\text { Azul }\end{array}$ & $\begin{array}{l}\text { Azul } \\
\text { celeste }\end{array}$ & $\begin{array}{l}\text { Estofado } \\
\text { Blanco }\end{array}$ & \multirow{4}{*}{$\begin{array}{c}\text { Veladuras } \\
\text { blancas } \\
\text { Rosa pálido } \\
\text { Imprimación } \\
\text { Blanca }\end{array}$} & \\
\hline & & Oro & Oro & Oro & Oro & Oro & & \\
\hline & & Bol & Bol & Bol & Bol & $\mathrm{Bol}$ & & \\
\hline & & Estuco & Estuco & Estuco & Estuco & Estuco & & \\
\hline \multirow{5}{*}{$\begin{array}{l}\text { Primera } \\
\text { Policromía }\end{array}$} & Rosa pálido & Blanco & & Azul & & Estofado blanco & Rosa intenso & Azul \\
\hline & \multirow{2}{*}{$\begin{array}{c}\text { Imprimación } \\
\text { amarillenta }\end{array}$} & Oro & Oro & Oro & Oro & Oro & \multirow{2}{*}{$\begin{array}{l}\text { Imprimación } \\
\text { rosaamarillenta }\end{array}$} & Oro \\
\hline & & Bol & Bol & Bol & Bol & Bol & & Bol \\
\hline & Preparación & Preparación & Preparación & Preparación & Preparación & Preparación & Preparación & Preparación \\
\hline & Pasta papel & Tejido & Tejido & Tejido & Tejido & Tejido & Pasta papel & Tejido \\
\hline
\end{tabular}

dos de hierro rojos. En las diversas capas de color coincide la utilización de aceite de linaza como aglutinante del pigmento. Entre los pigmentos identificados en las vestiduras de la Virgen y el Niño se detectó la presencia de azul ultramar artificial mezclado con blanco de plomo en menor proporción.

Con el fin de obtener una mayor información sobre la sucesión de policromías existentes el análisis estratigráfico ha sido complementado con el estudio de correspondencia de capas policromas. Tras una observación minuciosa de la superficie policroma fueron seleccionados los II puntos posteriormente examinados con microscopio binocular coincidiendo todos ellos con los bordes de las lagunas existentes. Ha sido detectada otra policromía subyacente de características cromáticas similares a la que se aprecia en superficie en prácticamente la totalidad de la escultura. La secuencia de estratos observados queda reflejada en una serie de gráficos donde además de una descripción se dibuja el aspecto que presenta cada uno de ellos.

\section{Historia material}

8. Archivo Palacio Arzobispal de Sevilla. Sección: Administración General. Serie: Visitas. Legajo, |347. Libro I 355.

9. Archivo de la Hermandad de la Virgen de los Remedios. Copia de la donación del frontal de plata a la Virgen de los Remedios, realizada por el seminarista don Francisco Infante de Cos el 23 de agosto de 1935.

10. López Martínez, C.: Desde Martínez Montañés hasta Pedro Roldán. Sevilla, 1932. Pág. 63.
La ubicación original de la imagen, tal como refiere la leyenda sobre su origen, pudo ser la iglesia parroquial hasta que se construyó su capilla y hospital gobernado por la hermandad de la Misericordia. Esta cofradía tuvo su sede en la ermita de Nuestra Señora de los Remedios, según consta en los libros de visitas conservados en el Archivo del Palacio Arzobispal de Sevilla ${ }^{8}$.

El origen de la hermandad de la Virgen de los Remedios no está muy claro pero es probable que la cofradía de la Misericordia tuviese a su cargo el cuida- do y la organización de los cultos de la Virgen. Ya que en 1675 Pedro Jiménez Delgado, vecino de Villarrasa, hizo donación de un frontal de altar, otros enseres y ornamentos a la Virgen de los Remedios para el servicio de su altar y se especifica en el documento que está colocada en la cofradía de la Misericordia 9 . Este frontal se conserva en la actualidad.

La referencia más antigua que se conoce de la ermita data de 1643, año en que dos vecinos de Villarrasa contratan con el maestro ensamblador Francisco Jiménez de la Barrera la realización de un retablo para la ermita de Nuestra Señora de los Remedios ${ }^{10 .}$

La imagen ha permanecido siempre en este lugar a excepción del periodo de la guerra civil española durante el cual, para evitar su destrucción, fue pasando por las distintas casas del pueblo. Entre ellas estuvo en un pajar de una vivienda situada en la misma calle de la ermita.

A través de la documentación gráfica y bibliográfica consultada para la realización de esta investigación, hemos podido conocer que la escultura ha sido restaurada y modificada en varias ocasiones.

Una de las transformaciones más importantes estuvo motivada posiblemente por el hecho de haberles colocado tanto al Niño como a la Virgen ojos de cristal. Esta intervención no está documentada pero es posible que se realizara en el siglo XVIII ya que a partir de esta época es frecuente el empleo de ojos de cristal en las imágenes.

Como consecuencia de esto, se modificó entonces el volumen de la cabeza del Niño y fue mutilada la primitiva corona que debió tener la Virgen semejante a 


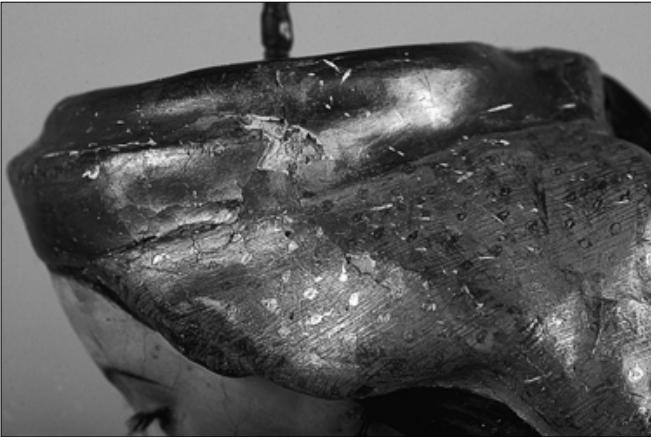

la de la Virgen del Socorro de Antequera. Además se conserva un grabado de la Virgen de los Remedios fechado en 1760 en el cual aparece ya con una corona de orfebrería. (Fotos I I y |2.)

También hay referencia documental de otras restauraciones, en el año |86| consta que se pintó, doró y se le hizo algo de escultura por el artista Astorga, quedando la imagen enteramente renovada en el exterior "I.

Ya en nuestro siglo es restaurada en 1913 por Carlos González de Eiris, como recoge la inscripción que tiene la escultura en el reverso.

A través de unas fotografías de la imagen realizadas en las décadas de los años 50 y 60 es posible apreciar cómo se conservaba todavía en buen estado el estofado de las vestimentas, pero las carnaciones presentaban grietas y algunas pérdidas.

Posteriormente es intervenida de nuevo en 1967 por el artista sevillano José Rivera García que consolidó con cola y cubrió las grietas, estofó lo imprescindible el manto y encarnó el rostro de la Virgen ${ }^{12}$.

En 1988 Antonio García Romero le añadió una pieza de madera en la parte posterior con la finalidad de reforzar el reverso de la escultura, ya que sobre éste se anclaba directamente el sistema de sujeción del manto y de las ráfagas. (Fotol 0.)

El proceso de restauración-conservación llevado a cabo en el I.A.P.H. ha aportado además otros datos acerca de las restauraciones y modificaciones que ha sufrido la imagen.

De esta manera hemos podido comprobar que la peana inferior no forma parte del original ya que la tabla que cierra la escultura por el reverso sólo llega hasta la peana semicircular. (Foto I3)

Mediante el estudio de correspondencia de capas policromas no se ha podido confirmar la presencia de un estrato dorado en la policromía subyacente de los cabellos, debido al deterioro que presentaban los bordes de las lagunas examinados. Al ser ésta una característica propia de las imágenes marianas de la época, podemos suponer que originariamente los cabellos de la Virgen y el Niño fueran dorados, como apreciamos en la Virgen del Socorro de Ante-
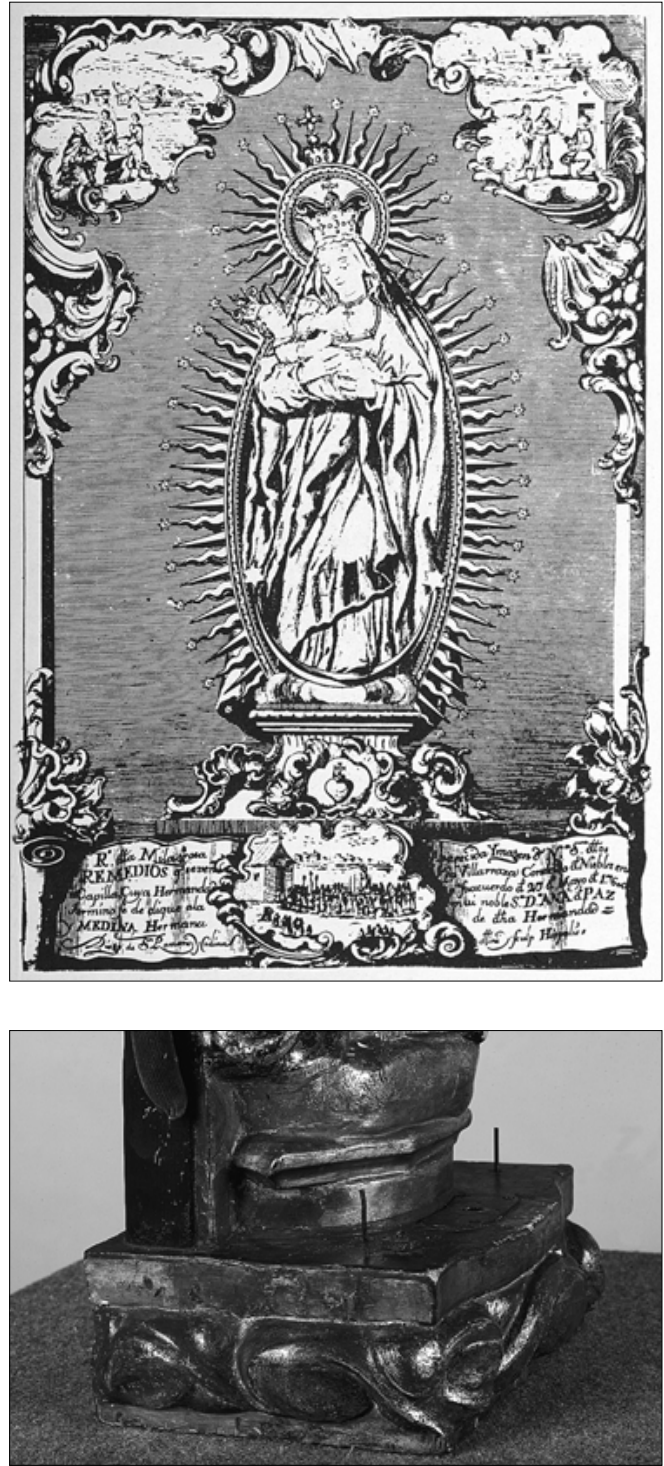

quera. Sí se ha constatado la existencia de dos capas de policromía tanto en las carnaciones como en las vestimentas.

También por mediación de los análisis químicos se ha identificado el azul ultramar artificial entre los pigmentos que componen el último estofado aplicado a las vestimentas de la Virgen. Este tipo de pigmento se empezó a fabricar hacia 1830, de lo que se deduce que los estofados que presenta la Virgen en la actualidad fueron realizados con posterioridad a esa fecha.

Además de estas restauraciones a través de grabados se tienen datos de que desde el siglo XVIII se revestía a la Virgen y se le colocaba una corona de orfebrería, como muestra el grabado de 1760, en el cual se aprecia que el Niño también debió llevarla, siendo sustituida luego por unas potencias según aparece en otro grabado fechado en 1857. De hecho la cabeza del Niño en su parte superior presentaba dos agujeros probablemente correspondientes a estos ornamentos. (Fotos 14 y I5.) $\varangle$

4

음

I. Cabeza Virgen de los Remedios. Detalle de la corona mutilada.

12. Grabado de la Virgen de los Remedios 1760.

13. Detalle de la peana añadida a la imagen. También se aprecia el volumen adosado sobre el reverso.

I I. González Gómez, J. M. y Carrasco Terriza, M. J.: Op. Cit Pág. 402.

12. Ibidem 

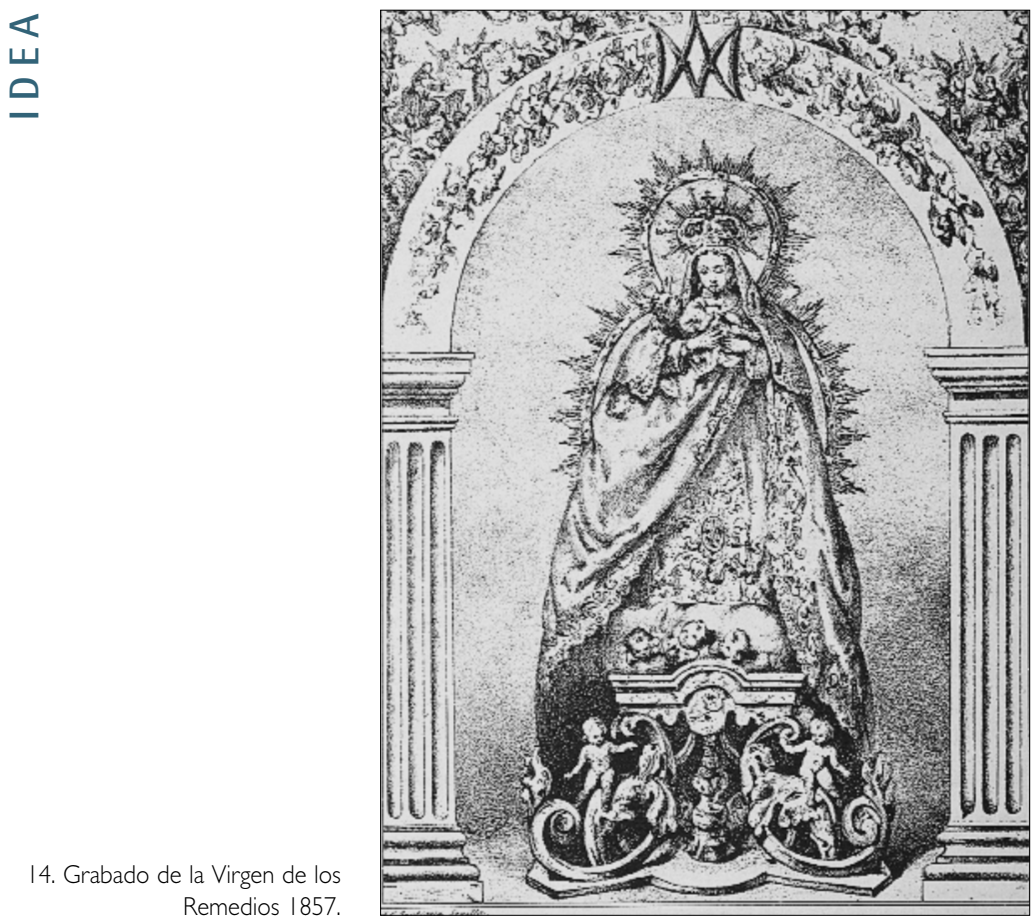

15. Cabeza del Niño. Detalle del estado de conservación.

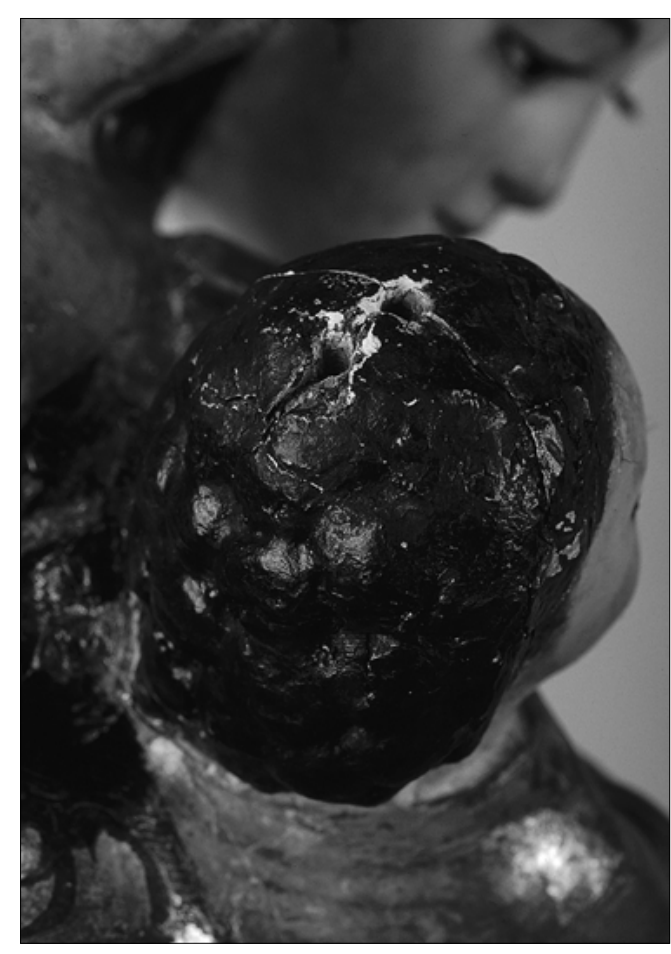

\section{Estado de conservación}

Con este examen se pretenden determinar las alteraciones que presenta la escultura en sus diferentes estratos así como analizar las causas que las han provocado.

\section{Alteraciones del soporte}

Las principales alteraciones detectadas fueron las grietas y fisuras originadas en el soporte de tela y pasta de papel debido a su fragilidad y su naturaleza higroscópi- ca, influenciada por los cambios de humedad y temperatura. Las grietas de mayor relevancia se localizaron en el cuello y cabeza del Niño seguramente provocadas por la tensión que ejercía el peso de las potencias. La grieta que recorre transversalmente la sección del cuello provoca la movilidad del conjunto. Se aprecian también numerosas fisuras en los laterales de la escultura al ser esta zona la superficie de contacto habitual en la manipulación de la escultura y la que sufre todas las tensiones transmitidas por el pollero fijado al reverso en su uso procesional. (Foto I5.)

En el soporte de madera que constituye la peana se detectó un ataque puntual de insectos xilófagos en la base de la escultura.

La imagen de la Virgen de los Remedios ha sufrido a lo largo de su historia material, como se ha comentado anteriormente, varias modificaciones morfológicas entre las que destaca la posible mutilación de la corona original cuando se introducen en el s. XVIII ojos de cristal. Seguramente también en aquel momento se suplementa a la escultura la actual peana utilizando como fijación gran cantidad de elementos metálicos. En la última intervención realizada en 1988 se adosa a toda la superficie del reverso de la imagen una pieza de madera a modo de refuerzo aumentando el espesor original hasta $6,5 \mathrm{~cm}$.

\section{Alteraciones de la preparación, película de color y} capa de protección

Se han originado cuarteados y fisuras en el estrato de preparación repartidas por toda la escultura, acentuándose en las superficies más deterioradas del soporte de tela y pasta de papel subyacente: laterales de la escultura y carnaciones. Los levantamientos de la preparación y película de color y las perdidas de la policromía coinciden también con las zonas de grietas. La fragilidad del soporte subyacente junto con su propiedad higroscópica ante los cambios de humedad y temperatura han sido entre otras las causas directas de su alteración.

En intervenciones anteriores se aplicó, con la intención de reforzar la cabeza y cuello del Niño, una gruesa capa de estuco que ocultaba parte de la policromía original. (Foto 16)

Las perdidas de la película de color coinciden con las lagunas del estrato de preparación, a excepción de las vestiduras de la Virgen y el Niño donde los estofados han sufrido desgastes generalizados perdiéndose prácticamente los motivos decorativos esgrafiados. Los desgastes de la policromía originados en el zapato y parte inferior de la túnica de la Virgen han sido principalmente causados por el roce de la imagen en el acto del besapié. (Foto 17)

Sobre la película de color se localizan numerosos repintes parciales en prácticamente toda su superficie y de forma más generalizada a modo de repolicromía imitando los estofados perdidos en el manto de la 


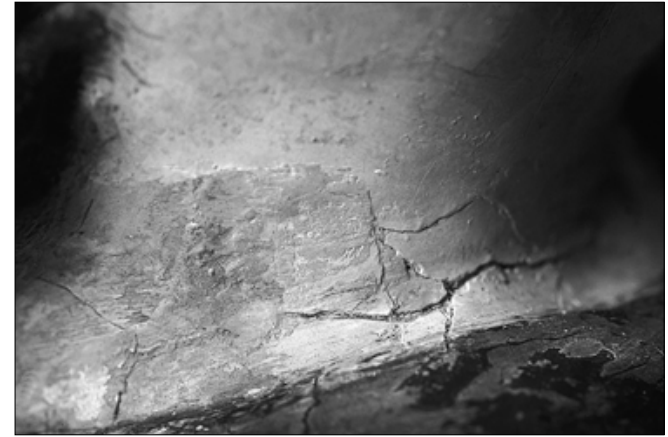

Virgen. En las carnaciones destaca por sus dimensiones el repinte que recubre la policromía del cuello y el escote de la Virgen sobrepasando el tamaño de la laguna detectada en la radiografía. (Foto | 8)

La policromía de las carnaciones presentaba de forma más acusada un oscurecimiento generalizado originado por la acumulación del humo procedente de velas y la oxidación del estrato de goma laca irregularmente aplicado en superficie. (Foto 19)

\section{Tratamiento realizado}

Finalizada la fase de estudios previos se elaboró la propuesta de tratamiento a aplicar en cada uno de los estratos y seguidamente iniciamos la fase de intervención propiamente dicha sobre la escultura.

Los criterios de intervención aplicados han tenido fundamentalmente un carácter conservativo con la finalidad de eliminar y frenar los procesos de deterioro activos.

Por otro lado se han aplicado criterios de restauración para devolverle a la escultura la unidad estética perdida teniendo presente en el alcance de la intervención el carácter devocional de la imagen. Los tratamientos y materiales empleados se han mantenido siempre fieles a los principios de reversibilidad, estabilidad y diferenciación de los estratos originales.

\section{Soporte}

La desinsectación de la escultura se realizó mediante gases inertes y posteriormente fue aplicado, mediante impregnación e inyección, un producto preventivo sobre la base de la escultura que disminuya el riesgo de nuevos ataques biológicos.

También se llevó a cabo la consolidación material de las finas fisuras originadas en el soporte de tela encolada mediante la inyección de cola de conejo. Las grietas y orificios que presentaba el soporte de pasta de papel principalmente en la cabeza y el cuello del Niño fueron resanadas introduciendo fibras de papel de lino y abacá aglutinadas con cola animal.

Unicamente se ha sustituido un gran tornillo visible que atravesaba la peana inferior por una espiga de haya de
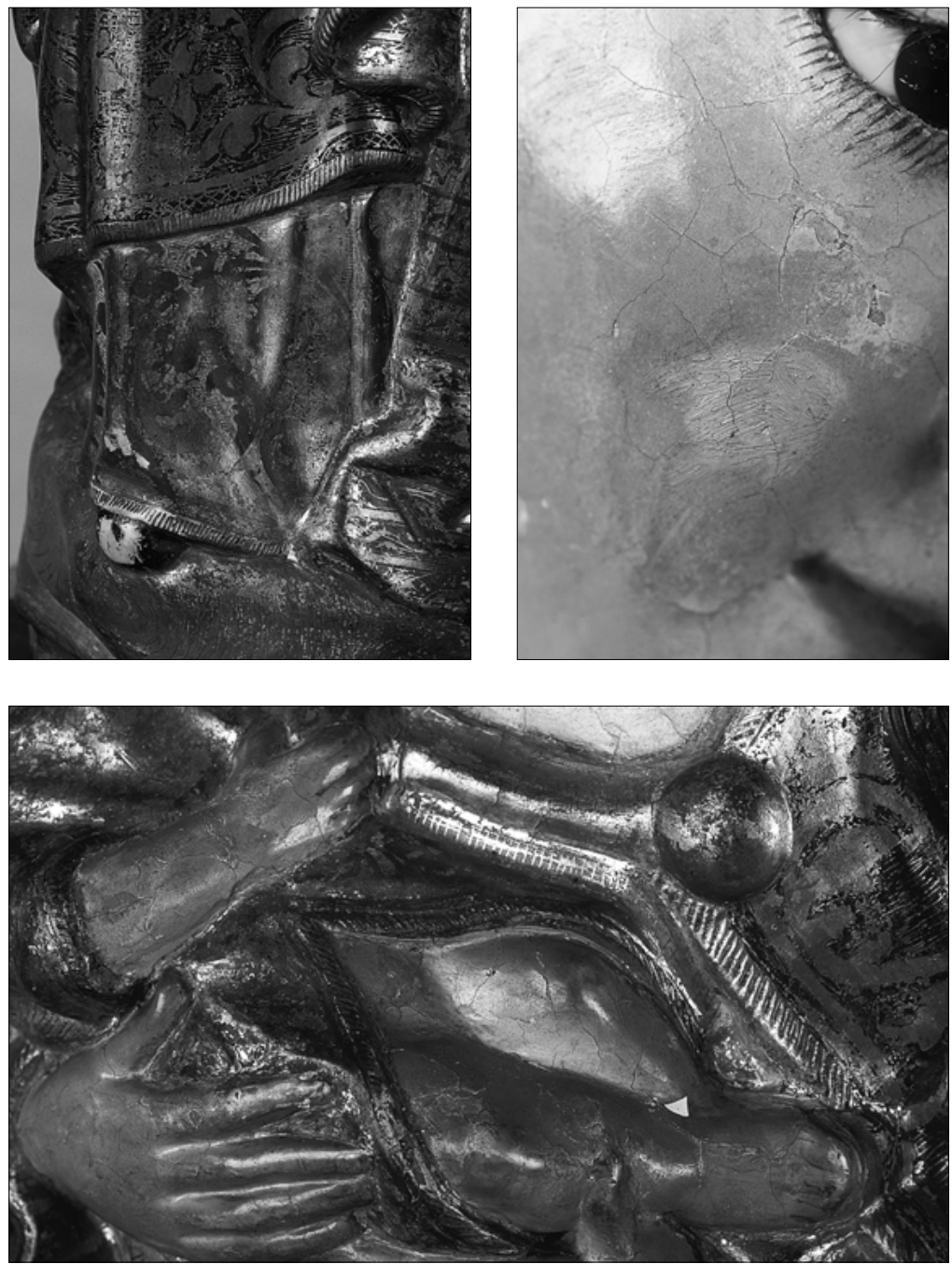

16. Detalle del cuello del Niño. Proceso de eliminación de la

I cm de grosor. No se aprecian en el estudio radiográfico alteraciones provocadas por el resto de los elementos metálicos existentes en el interior del soporte. Resane de agujeros de la peana de madera con serrín de madera de cedro y acetato de polivinilo.

Los escasos restos de pestañas y el soporte de cartón adherido a los párpados del Niño fueron eliminados. Las pestañas de la Virgen, muy deterioradas, se sustituyeron por otras de pelo natural de similar tonalidad a los cabellos y cejas.

\section{Preparación, película de color y capa de protección}

La limpieza de la suciedad superficial acumulada se ha efectuado con brocha suave.

Una vez comprobada la resistencia de la película de color al medio acuoso se procedió a la fijación de la capa de preparación y película de color con problemas de adhesión mediante cola de conejo y una leve presión. De forma previa al proceso de fijación fue necesario proteger el estofado azul del manto con Paraloid diluido al $4 \%$ en Tolueno ya que se observó una falta de cohesión de los pigmentos. gruesa capa de estucos

17. Detalle de los desgastes de la policromía.

18. Detalle del rostro de la Virgen. Repinte parcial.

19. Estado inicial de las carnacioción del estrato de barniz. nes. Suciedad superficial y oxida- 
$\longleftarrow$
$\square$

20. Detalle del proceso de limpieza.

21. Proceso de estucado.

22. Proceso de limpieza Detalle de las manos de la Virgen.

23. Estado final tras la intervención.
Antes de proceder a la limpieza se realizaron tests de disolventes de menor a mayor fuerza sobre la superficie policroma observando su eficacia bajo el microscopio binocular y seleccionar así los más adecuados en cada caso. Seguidamente se efectuaron catas en diferentes zonas para fijar el nivel de limpieza deseado. (Fotos 20 y 22)

La eliminación de los repintes que parcialmente recubrían las carnaciones de la Virgen y el Niño se realiza mediante limpieza química con disolventes adecuados a cada zona. Fue eliminado el burdo repinte que ocultaba prácticamente la totalidad de la carnación del escote de la Virgen y que se extendía hasta el cuello.
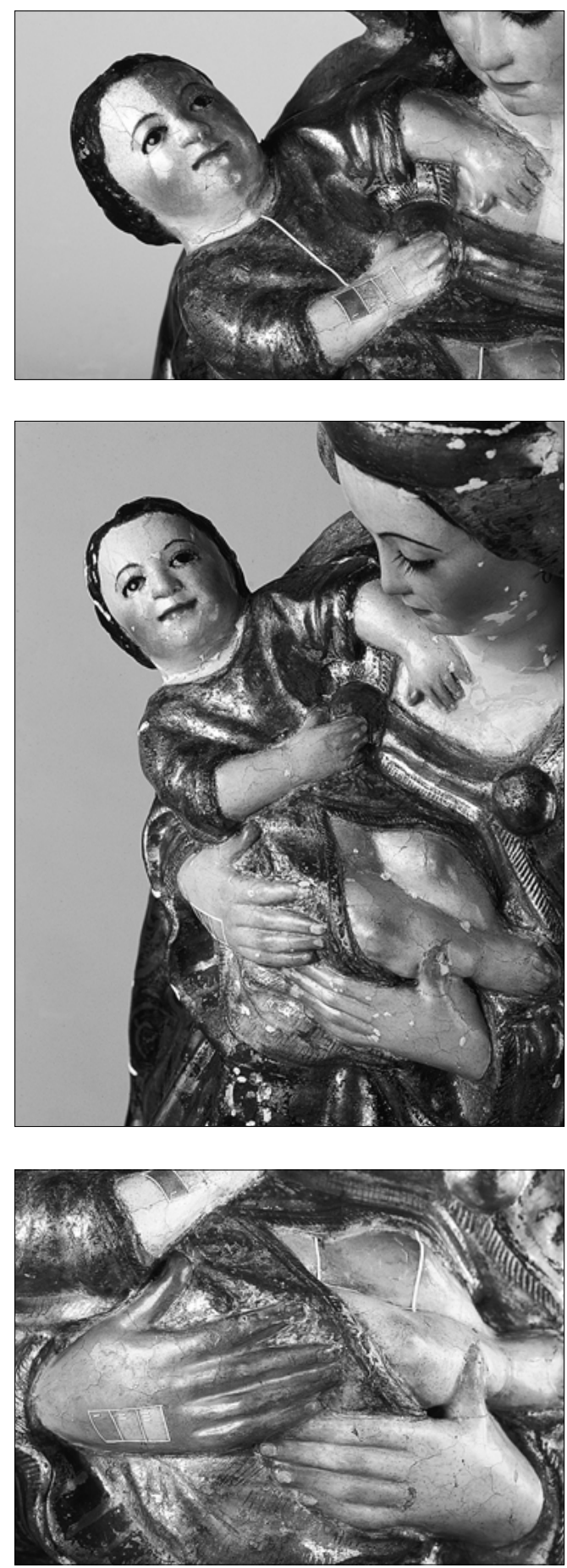

Se estucaron las lagunas con aparejo tradicional y se realizó la reintegración cromática de las mismas, mediante acuarela y una técnica identificable a corta distancia (regattino). La laguna del escote de la Virgen se reintegró con pigmentos al barniz debido al carácter oleoso del estrato subyacente. Con la finalidad de integrar esta laguna a la policromía del resto de la escultura se aplicó en esta zona una tinta plana. Se adoptó este criterio debido al carácter devocional de la imagen y al ser esta una zona muy visible. (Foto 2l)

Finalmente se aplicó a brocha sobre la escultura una capa de protección final consistente en resina sintética en esencia de petróleo.

\section{Conservación preventiva}

Hay que resaltar la importancia que tienen en esta imagen, debido a la fragilidad de su soporte, la adopción de medidas que contribuyan a disminuir al máximo su deterioro.

Por esta razón se sustituyó el antiguo pollero por una nueva estructura en aluminio para la colocación del manto que permite que la escultura se encuentre totalmente independiente y no soporte las tensiones de su peso. La nueva estructura sirve de anclaje a las ráfagas y a la corona que antes se fijaban directamente a la escultura.

Además se colocó una plataforma metálica con asas adaptada a la base de la escultura lo que permite la manipulación de la imagen, reduciendo al mínimo el contacto con la obra.

La corona del Niño se fijó mediante un perno de $4 \mathrm{~mm}$ de diámetro a una rosca hueca inoxidable embutida en la cabeza, evitando así la abrasión continua que se producía en el frágil soporte.

Por último se dieron una serie de medidas para el mantenimiento óptimo de la escultura, entre ellas se puede destacar la recomendación de evitar el acto del besapié para no provocar desgastes en la policromía. También se aconseja evitar la aproximación de velas para no contribuir a un nuevo ennegrecimiento de la policromía.

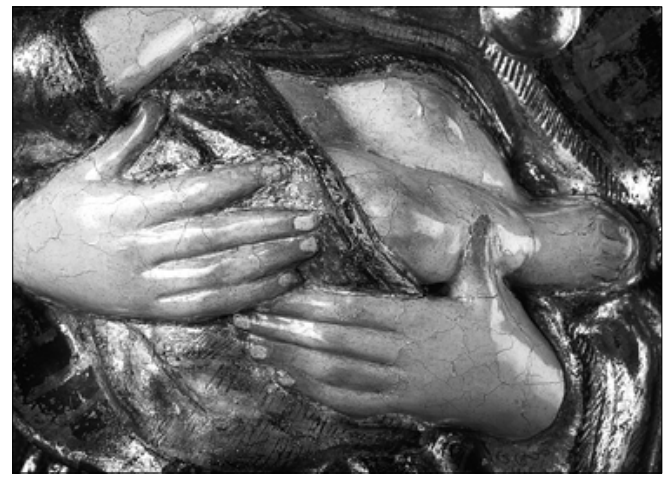




\section{Conclusiones}

En conclusión podemos confirmar que la Virgen de los Remedios aunque es una obra con ciertas resonancias nórdicas fue realizada por un artista español entre finales del siglo $\mathrm{XV}$ y principios del $\mathrm{XVI}$ a partir de un modelo europeo. Mediante el análisis estilístico se ha comprobado que la imagen muestra unos rasgos propios de las esculturas marianas de esa época. Y además a través del estudio comparativo y de los métodos físicos y científicos de examen se ha constatado que la Virgen de los Remedios presenta una serie de características, técnicas y morfológicas, que son comunes a otras imágenes españolas de la misma época con reminiscencias nórdicas.

El proceso de intervención ha servido para profundizar en el conocimiento de la técnica de ejecución de la imagen. A través del estudio técnico y estilístico comparativo con la Virgen del Socorro de Antequera planteamos la hipótesis de que estas obras pudieran ser realizadas por un mismo artista a partir de un molde utilizado en ambos casos.

Nuestro trabajo ha generado numerosos datos que esperamos sean el punto de partida para nuevas investigaciones que permitan un mayor conocimiento tanto del origen histórico de estas obras como de su técnica mixta de ejecución.

\section{Bibliografía}

ARIAS MARTÍNEZ , M; HERNÁNDEZ REDONDO, J. I; SANCHEZ DEL BARRIO, A. Semana Santa en Medina del Campo. Historias y obras artísticas. Nazareno de la Cruz. Medina del Campo, 1996.

FLORES DE MEDEIROS, Gilca: Our lady of Delivery. Restauration of a tella encolada Scuplture. Prepirints ICOM. I Ith Triennal Meeting, Edingurg Scotland. September 1996.

QUEREJAZU LEYTON, Pedro : La escultura en maguey, pasta y tela encolada en Bolivia y Perú. Actas del II Congreso de Bienes Culturales. Teruel, junio 1978.

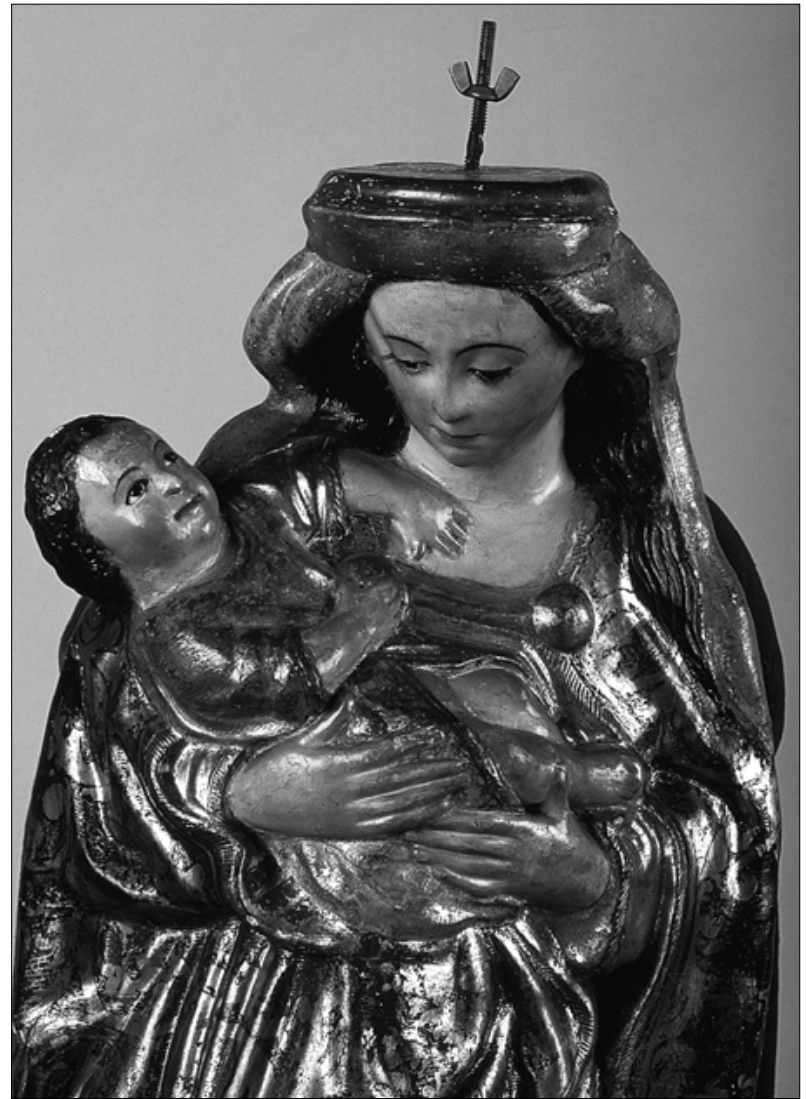

24. Detalle del estado inicial.

Ficha técnica

Estado de conservación, propuesta de tratamiento, tratamiento realizado y documentación gráfica:

Gracia Montero Saucedo, restauradora.

Dpto. de Tratamiento. Centro de Intervención del I.A.P.H.

Coordinación del trabajo:

Enrique Gutiérrez Carrasquilla, restaurador.

Dpto. de Tratamiento. Centro de Intervención del I.A.P.H

Estudio histórico artístico:

Eva Villanueva Romero, historiadora.

Dpto. de Investigación. Centro de Intervención del I.A.P.H.

Documentación fotográfica:

José Manuel Santos Madrid, fotógrafo.

Dpto. de Análisis. Centro de Intervención del I.A.P.H.

Documentación radiográfica:

Eugenio Fernández Ruiz, fotógrafo.

Dpto. de Análisis. Centro de Intervención del I.A.P.H.

Estudios analíticos:

Estudio estratigráfico María Luisa Franquelo Zoffmann, química. Identificación de fibras textiles Lourdes Martín García, química. Análisis biológico Marta Sameño Puerto, bióloga.

Dpto. de Análisis. Centro de Intervención del I.A.P.H.
$<$

니 